\title{
Open Letter to Members of the A.C.R.L.
}

T viEw of transportation difficulties, 1 librarians, like other professional groups, are making drastic changes in their plans for travel. The opportunity to hold state, regional, and national meetings will be materially affected for the duration.

How can we make the best of this situation? It would be regrettable if a transportation problem prevented members of a profession such as ours from interchanging ideas as we are accustomed to do.

A suggestion comes from the editors of College and Research Libraries. It is that college and reference librarians make the best of this situation by substituting discussions in their journal for public discussions at regular meetings.

This proposal offers a means of coping successfully with the transportation problem. Accordingly, word has gone out to all of those who would ordinarily be in charge of programs, asking them to go ahead and arrange for discussions of timely interest to librarians to be prepared. The purpose of this statement, addressed to the membership as a whole, is to call to your attention the efforts that are being made to continue professional intercommunication under the present adverse conditions.

While the planning of discussions for possible publication in College and $R e-$ search Libraries has many points in common with planning regular programs, there are two differences that should be pointed out. The first is that all papers submitted to College and Research Libraries will, of course, have to be written out in full. They should be complete in every detail and ready to go to the printer. The second is that competition for space will mean that probably some of the papers will not be published. For the guidance of those who plan the discussions and of those who write the papers, the editors have listed the following as among the most important questions in terms of which papers will be selected for publication.

I. Does the paper, when considered along with others available for use, help cover the whole field of work represented by College and Research Libraries?

2. Does the discussion have substance. point? Is it a real contribution?

3. Is the method of treatment sound? Is it a good prose composition?

4. Does it contribute anything not already to be found in library literature?

5. Do we have space for it? Is it too long or unnecessarily long?

I should like to encourage all members of the A.C.R.L. and particularly all duly organized sections to accept the challenge thus presented to us by our own journal and to make it as effective a substitute as we can for the discussions to which we are accustomed at our regular meetings.

\section{Mabel L. Conat, President}

